\title{
Eccrine poroma and porocarcinoma on the same unusual location: report on two cases*
}

\author{
Han $\mathrm{Ma}^{1}$ \\ Rongbiao $\mathrm{Lu}^{1}$
}

\author{
Mengsi Liao $^{1}$ \\ Chun $\mathrm{Lu}^{1}$
}

Shu Qiu ${ }^{1}$

DOI: http:/ / dx.doi.org/10.1590/abd1806-4841.20153415

\begin{abstract}
A bstract: Eccrine poroma is a benign adnexal tumour of the uppermost portion of the intraepidermal eccrine sweat gland duct and acrosyringium. Eccrine porocarcinoma is the malignant phenotype arising from the intraepidermal portion of the eccrine sweat gland duct epithelium or from pre-existing eccrine poroma. Both commonly occur in the palms or sides of the feet; these areas have a high concentration of eccrine sweat glands. We describe two respective cases of benign and malignant eccrine poroma on the scrotum, which entailed good excisional results.
\end{abstract}

Keywords: Eccrine glands; Eccrine porocarcinoma; Poroma; Scrotum

\section{INTRODUCTION}

Eccrine poromas (EP) derive from the intraepidermal portion of eccrine sweat ducts. It is an uncommon pathologic condition that appears predominantly between the fourth and sixth decades of life. There is a malignant variant, eccrine porocarcinoma (EPC), which may be a primary tumor, but generally results from the malignant transformation of EP. ${ }^{1}$ Both commonly occur in the palms or sides of the feet; these areas have a high concentration of eccrine sweat glands. We describe two respective cases of EP and EPC on the scrotum, which entailed good excisional results.

\section{CASE REPORT}

\section{Case 1}

A 28-year-old man presented a soft reddish mass on the left side of the scrotum for one year (Figure 1A). The surface of the tumor was irregular (Figure $1 B)$. The lesion grew gradually and was not associat- ed with pain or any other symptoms. Physical examination revealed no sign of enlargement of superficial lymph nodes in the bilateral parts of the groin. On the basis of clinical features, a diagnosis of benign etiology was made and the lesion was biopsied. Histological examination revealed a well-circumscribed nodule (Figure 1C) composed of small, monomorphous cuboidal poroid cells with eosinophilic cytoplasm and monomorphic nuclei (Figure 1D). Histopathologic findings allowed us to establish the diagnosis of eccrine poroma.

\section{Case 2}

A 54-year-old man had had an asymptomatic, well-circumscribed, firm, superficially ulcerated and crusting, reddish-brown plaque on the right side of the scrotum for two years (Figure 2A). The lesion had increased in size to $3.2 \mathrm{~cm} \times 2.2 \mathrm{~cm}$ and a reddish-pink,

Approved by the Advisory Board and accepted for publication on 21.05.2014

Work performed at the Department of Dermatology Third Affiliated Hospital, Sun Yat-sen University - Guangdong, China.

Financial Support: None.

Conflict of Interest: None.

1 Third Affiliated Hospital, Sun Yat-sen University - Guangdong, China.

(C)2015 by Anais Brasileiros de Dermatologia 

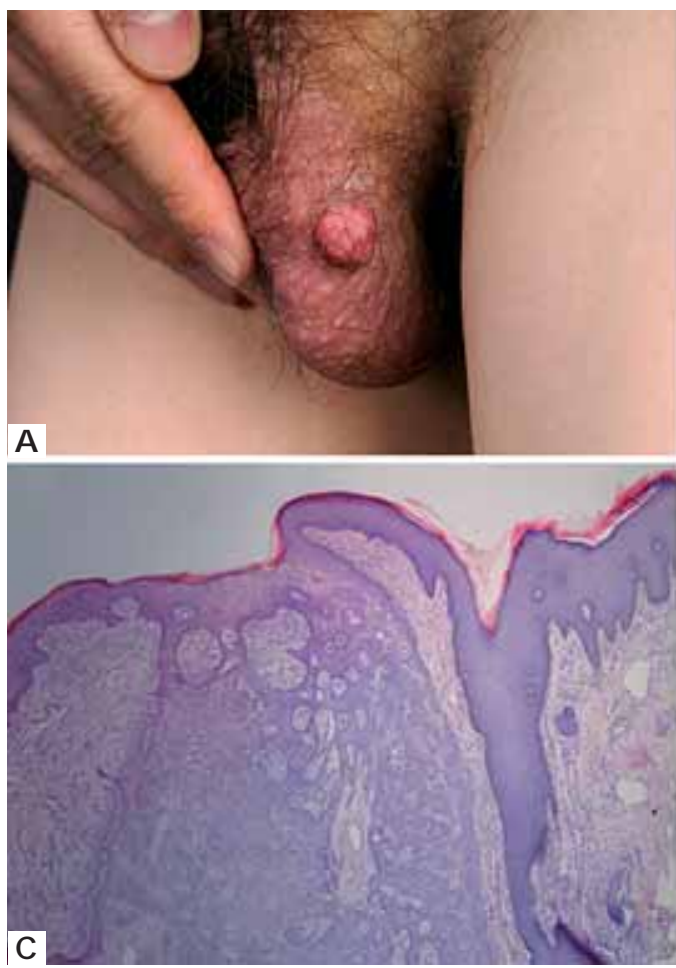
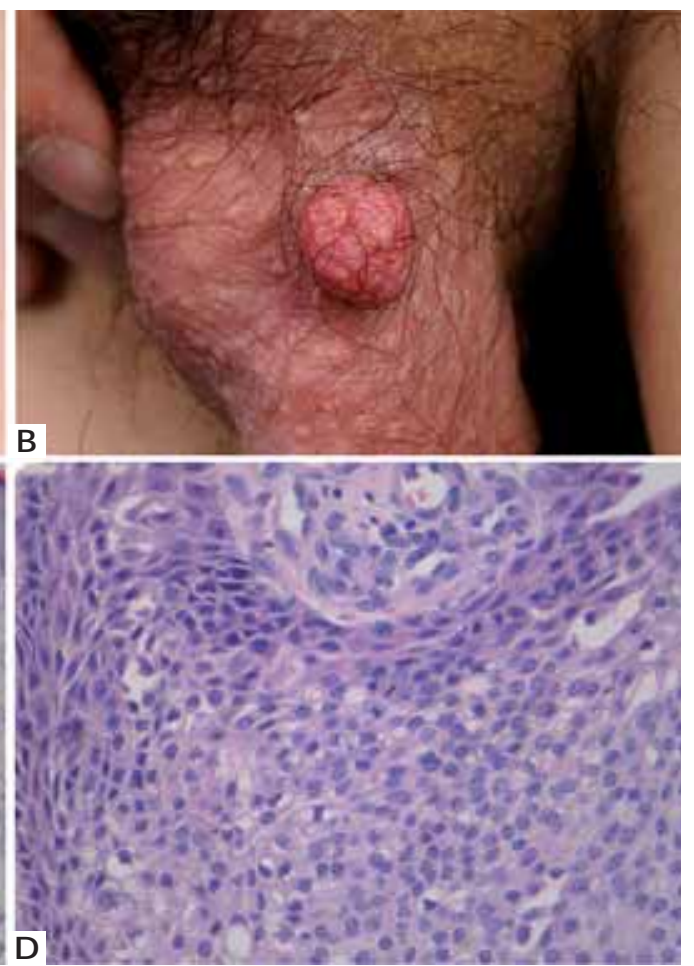

FIGURE 1:

A. Reddish mass on the left scrotum; B. Irregular surface; C. HE: wellcircumscribed nodule with tubular structures and cystic spaces; D. HE: small, cuboidal poroid cells with eosinophilic cytoplasm and monomorphic nuclei verrucous nodule arose progressively from the external portion (Figure 2B). Recently, it started to bleed when traumatized. No history of trauma in the area could be elicited. Physical examination did not show any regional lymphadenopathy. The tumor was surgically removed. Histological examination revealed many nests of small, cuboidal poroid cells with eosinophilic cytoplasm and monomorphic nuclei in the dermis, and in some areas tumor cells invaded the epidermis (Figure 2C). Tubular structures and cystic spaces were present within the neoplasm (Figure 2D). Mucin deposits were found in the ground subtance of the dermis around the tumor nests (Figure 2E). Mitoses were easily seen within the neoplasm (Figure 2F). Immunohistochemical staining revealed that tumor cells were positive for EMA, P53, P63 and Ki-67 (>70\%) (Figures $2 \mathrm{G}, 2 \mathrm{H}, 2 \mathrm{I}$ and $2 \mathrm{~J})$. The diagnosis was eccrine porocarcinoma with intraepidermal growth.

\section{DISAUSSION}

Eccrine poroma was first reported by Pinkus et al. in 1956. Sweat gland tumors represent $1 \%$ of all primary skin lesions, and eccrine poroma makes up 10\% of these. It usually occurs as a solitary, dome-shaped, skin-colored or pigmented, slow-growing, sessile papule or nodule, situated mostly on the soles or sides of the feet. However, eccrine poromas have been found on hairless surfaces of the extremities, chest, back, head, and neck. ${ }^{2}$ The scrotum is an extremely uncommon primary location for the disease.

Although EP is known to be benign, it can slowly become a malignant tumor. The ratio of malignant transformation from EP into EPC is 18\%, as reported by Robson et al. ${ }^{3}$ The two diseases can be seen as a consecutive disease in different phases. However, EPC does not always arise from EP. It sometimes develops de novo, without any preexisting lesion. Clinically, EPCs are seen more often in elderly individuals aged over 60 , with a female predominance. Furthermore, the most common EPC sites are the limbs, especially the lower limbs, and scalp. ${ }^{4}$

It is not difficult to differentiate EPC from EP, but EPC can be confused with other malignant diseases, such as squamous cell carcinoma and ulcerated basal cell carcinoma. A good resectional biopsy is necessary, and the existence of ductual differentiation under microscopic examination may be helpful. However, some variants of EP exhibit malignant biological behaviors, such as an infiltrative growth pattern. ${ }^{3} \mathrm{Im}-$ portantly, while a bleeding tendency is seen as a hallmark of malignant transformation in tumors, this does not necessarily apply in this context. Because the lesions which clinically presented as verrucous plaques or polypoid growths are frequently ulcerated and occasionally bled upon trauma. ${ }^{5}$ 

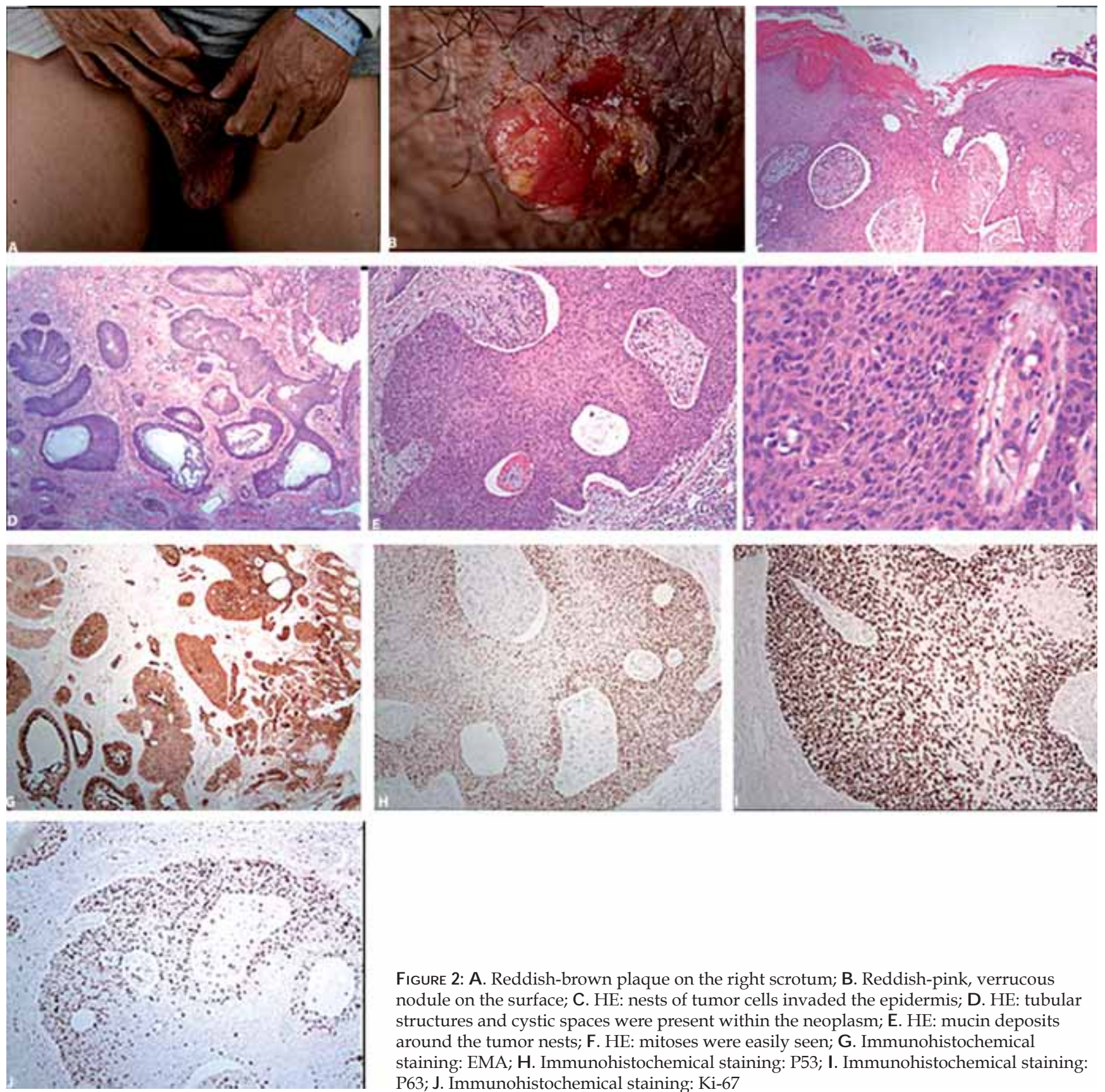

FIGURE 2: A. Reddish-brown plaque on the right scrotum; B. Reddish-pink, verrucous nodule on the surface; $\mathbf{C}$. HE: nests of tumor cells invaded the epidermis; $\mathbf{D}$. HE: tubular structures and cystic spaces were present within the neoplasm; E. HE: mucin deposits around the tumor nests; F. HE: mitoses were easily seen; G. Immunohistochemical staining: EMA; H. Immunohistochemical staining: P53; I. Immunohistochemical staining: P63; J. Immunohistochemical staining: Ki-67

The pathogenesis of EP and EPC is unknown. Actinic damage, trauma, radiation and the human papilloma virus (HPV) are believed to be involved. ${ }^{6}$ Chen SY et al. reported that cyclin D1, p-pRb, p53, p63 and p73 may play a role in the tumorigenesis of EP and EPC. In particular, overexpressed p53, p63 and p73 might contribute to the formation of both EP and EPC; they also reported that activation of cyclin D1-p-pRb, possibly in conjunction with p53 dysfunctions and/or its family, may play a role in malignant transduction to EPC from eccrine duct cells or preexisting EP.7 


\section{REFERENCES}

1. Almeida FC, Cavalcanti SM, Medeiros AC, Teixeira MA. Pigmented eccrine poroma: report of an atypical case with the use of dermoscopy. An Bras Dermatol. 2013:88:803-6.

2. Guimerá Martín-Neda F, García Bustínduy M, Noda Cabrera A, Sánchez González $\mathrm{R}$, García Montelongo R. A rapidly growing eccrine poroma in a pregnant woman. J Am Acad Dermatol. 2004;50:124-6.

3. Robson A, Greene J, Ansari N, Kim B, Seed PT, McKee PH, et al. Eccrine porocarcinoma (malignant eccrine poroma): a clinicopathologic study of 69 cases. Am J Surg Pathol. 2001;25:710-20.

4. Huet P, Dandurand M, Pignodel C, Guillot B. Metastasizing eccrine porocarcinoma: report of a case and review of the literature. J Am Acad Dermatol. 1996;35:860-4.

5. Shaw M, McKee PH, Lowe D, Black MM. Malignant eccrine poroma: a study of twenty-seven cases. Br J Dermatol. 1982;107:675-80.

6. Johnson RC, Rosenmeier GJ, Keeling JH 3rd. A painful step. Eccrine poroma. Arch Dermatol. 1992;128:1530,1533.

7. Chen SY, Takeuchi S, Moroi Y, Kido M, Hayashida S, Qian Y, et al. Significance of cyclin D1-, product of retinoblastoma (pRb), p53, p63 and p73 expression in eccrine poroma and eccrine porocarcinoma. J Dermatol Sci. 2009;56:69-72.

M AILING ADDRESS:

$\mathrm{H}$ an $\mathrm{MA}$

$D$ epartment of D ermatology

Third A ffiliated H ospital

Sun $Y$ at-sen U niversity

N o. 600 Tianhe Road - Guangzhou

Guangdong, 510630, China.

E-mail: drmahan@sina.com

How to cite this article: Ma H, Liao M, Qiu S, Lu R, Lu C. Eccrine poroma and porocarcinoma on the same unusual location: two cases report. An Bras Dermatol. 2015;90 (3 Suppl 1): S69-72. 